\title{
MODELLING THE WAYS TO INCREASE THE CREATIVITY OF PSYCHOLOGY STUDENTS AS A BASIC FACTOR IN PROFESSIONAL DEVELOPMENT
}

\author{
Myroslav KRYSHTANOVYCH (iD ${ }^{1^{*}}$, Valentyna BILYK (10) ${ }^{2}$ Solomiia HANUSHCHYN (i] ${ }^{3}$, \\ Inesa SHEREMET (iD ${ }^{4}$, Kateryna VASYLENKO (iD ${ }^{5}$ \\ ${ }^{1}$ Lviv Polytechnic National University, Institute of Law, Psychology and Innovative Education, \\ Department of Pedagogy and Innovative Education, St. Kn. Romana 1/3, 79000, Lviv, Ukraine \\ 2, 4, 5 National Pedagogical Drahomanov University, Faculty of Pedagogy and Psychology, Department of \\ Medical Biological and Valeological Fundamentals of Health and Life Protection, \\ St. Turhenivs'ka 8/14, 01054, Kyiv, Ukraine \\ ${ }^{3}$ Lviv State University of Internal Affairs, Faculty of Psychology, \\ Department of Psychology and Management, St. Horodots'ka, 26, 79007, Lviv, Ukraine
}

Received 24 April 2020; accepted 2 November 2020

\begin{abstract}
One of the important tasks of the modern system of psychology in higher educational institutions is not only the development of student's professional potential but also the comprehensive development of their personality. The purpose of the article is to systematize the process of increasing the creativity of psychology students with the help of mechanisms and elements of the functional model of IDEF0. The novelty of this study lies in the fact that in the field of education, in particular, increasing such a subjective indicator as creative abilities, there has not yet been a methodology that allows forming an understandable and simple, but at the same time flexible system of actions. The reason for choosing this model was that it is the most visual and easy to understand for representatives of higher educational institutions. Also, this model is universal in terms of adding separate sublevels and subtasks, if for a particular educational institution it turns out to be incomplete or insufficiently detailed. Thus, it is the IDEF0 model that can reveal to the greatest extent such a subjective process as an increase in creativity among psychology students. The steps for increasing the creativity of psychology students are presented, which are the result of scrupulous analysis and many years of research by the authors in this area. The scientific contribution of this article can be considered the formation of a mechanism for increasing the creativity of psychology students, not in the context of creating a clear methodology, but in the context of forming a universal algorithm with poly-levels for detailing the goal.
\end{abstract}

Keywords: creative potential, creativity, model IDEF0, personal development, professional potential, professional training, psychology student.

\footnotetext{
*Corresponding author. E-mail: mf0077@ukr.net
} 


\section{Introduction}

Creativity is based on the ability that reflects the individual's properties to create new concepts and form new skills, i.e. ability to be creative. This concept is studied inextricably from the intellect and is associated with the creative achievements of the individual (Feist, 2010; Wells \& Dickens, 2020). Creativity is provided by a prime motivation, a conscious and shown interest, an active and independent position, healthy rivalry, hard work, and perseverance. It takes into account mobilization, informational, developing, orientation skills, the ability to generate ideas, technical ingenuity (Runco \& Acar, 2012).

The process of building creative potential is associated with the formation of a search apparatus and with the creation of objects to satisfy the general human needs. As a component, creativity is part of its self-regulation system. In this regard, human creativity is understood as such an integral property of a personality that arises as an internal premise of its creative activity (J. K. Smith \& L. F. Smith, 2010).

At the present stage of human development, highly professional creative specialists are needed, due to rapid changes in the socio-economic sphere of the country's public life. The question arises of a fundamental change in the system of training future professionals, which should focus on the challenges of everyday life and provide for their productive solution in the future. The problem of organizing educational activities of students is urgent since the leading goal of the modern system of higher education is the formation of a highly qualified and competitive specialist, who can to maximize the benefits of society to realize his creative potential, effectively and humanely solve diverse life problems that are becoming increasingly complex and unpredictable (Fekula, 2011).

In the process of professional development, the student faces the need not only to gain knowledge, skills, abilities in special disciplines but also to gain the ability creatively assimilate and use information, to crystallize a creative position on the implementation of their achievements in activities (Cheung et al., 2003). The process of personal integration and growth can be provided in different ways, and one of them is the orientation of a person towards creative potential, the resource that is an inexhaustible source of life force. The formation and identification of the creative abilities of psychology students today is the key to improving their professional training. Creativity can manifest itself both in life and in the ability to experiment in any area of knowledge (Welch et al., 2020).

The process of formation of student creativity is the acquisition by him the willingness to show directly creative activity, realize his creative potential, the actualization of individual traits of the carrier of situational creativity with the content of a socially significant type of activity, the manifestation of the highest degree of ability because eactions of striking creative mechanisms. And, according to Burkšaitienè (2018), this means that in the process of increasing student's creativity, a place should be occupied by:

- the actualization of the cognitive component organized as an active expansion of the intellectual sphere which is the basis for the formation of creative abilities;

- the formation of a conceptual-categorical apparatus for semantic manipulation of this in solving research, creative tasks that have the nature of problem situations;

- the wording of issues of a problematic nature, stimulating active mental activity;

- stimulating the development of erudition, broadening the horizons in the field of scientific knowledge of a diversified direction; 
- learning alternative thinking techniques (logical operations that help independently and creatively process the flow of information, come to conclusions, and not just adopt the arguments and statements that are ready);

- the organization of educational process as scientific research (according to the logic of organization, using methods), familiarization with various research procedures, and reflecting on their course. For the development of student's creativity, an unregulated environment with democratic relations and imitation of a creative personality are needed. Such development takes place under the influence of the microenvironment and imitation through the formation of a system of motives and personal properties (independence, motivation for self-actualization).

These components make it possible fully understand the backbone of the development and formation of student's creativity and in the future to form an integral structure and an algorithm for its increase.

Based on the personality-activity concept (development of personality as an individual), harmonious development of personality and efficiency, the productivity of professional activity is primarily associated with the problem of harmonious and creative integrity, the subjective and aim form of the image of a professional, in particular, this is especially important in the profession of a psychologist (Lopukhova, 2014; Navickienè et al., 2019).

But it is worth noting that the formation of most of the methods that are created to improve the functioning of processes in the education system always encounters the fact that factors such as the nature and individual characteristics of students always influence their effectiveness. That is why all the techniques that are formed on the basis of constant and rigorous algorithms will be doomed to short existence or, in general, from their first stages will become completely ineffective. That is why we have chosen the IDEF0 methodology, which not only makes it possible to visualize the process, but also makes it possible to do the local corrections.

Despite the fact that the IDEF0 model is mostly used in the description of computer technology processes and the construction of business algorithms, in our opinion, such a model can fully provide visibility and partially or completely systematize such a subjective process as increasing creativity, in particular, in psychologists, since despite the presence of a clear framework, in this model there is a constant opportunity to change and improve under the influence of external or internal factors of an individual higher educational institution.

The profession of psychologists is multifaceted, and most often it relies precisely on the creative abilities of the representatives of this profession. This is due to the fact that in the course of their professional activities, psychologists must quickly and correctly find an approach and solution to the problems of their patients (Baumeister et al., 2014).

Considering the above, the formation of a clear scheme for increasing the creativity of psychology students today is extremely important, therefore the purpose of the article is to systematize and to form the clear stages of the process of increasing the creativity of psychology students using the mechanisms and elements of the IDEF0 functional model. In this case, the basic methods of enhancing creativity among psychology students will differ under with the methodology of each teacher, but the backbone of the training system will be based on the proposed model. 


\section{Literature review}

The issues of increasing the creativity of psychology students have been considered for many years as a part of a general scientific search of ways to increase the student's creativity in higher educational institutions.

The problems of creativity and increasing its level among students were considered for a long time. In particular, Weisberg (1988) in his work revealed the basic principles and paradigms of an individual's creativity, including those who study in higher educational institutions.

In modern scientific research, you can find numerous of works devoted to the problems of student's creativity (Langebæk et al., 2020). For example, Entrialgo and Iglesias (2020) examined how important the role of creativity for entrepreneurship among students. Ling and Loh (2020) examined how creativity and critical thinking work for students in private schools in a particular country.

As a successful method for improving creativity among children in schools and students at universities, Renzulli (1992) proposed the methodology for stimulating creativity, according to which student can successfully and periodically increase his own level of creativity if certain success incentives and prerequisites act on it. Based on the scientific achievements of the presented work, in the following years, numeros of scientists realized the urgency of developing students' creativity. For example, Dickhut (2003) and Goodman (2015) in their works will smooth out the ways and methods of enhancing students' creative abilities by introducing cognitive-semantic techniques in the learning process. Zhang and Sternberg (2009) and Sanz de Acedo Baquedano and Sanz de Acedo Lizarraga (2012) in their work examined the main ways and style of enhancing students' creativity through the use of constant paradigms, the main participants of which were teachers and students. Consequently, the teacher was assigned the main role of the catalyst for the creativity of the student. The question of the role of a higher educational institution and teacher are highlighted in the works of Bruno and Dell'Aversana (2017) and Kondakov (2020), who studied the role of faculty in enhancing the creativity of psychology students. According to this work, this element is crucial in achieving success in this process.

But over time, this direction became so vast that scientists concluded that ways to increase creativity should be explored in the context of taking into account the characteristics of the future student profession. For example, Proctor and Capaldi (2001) and Shandruk (2020) in their works examined ways to increase creativity specifically among students in the psychological sphere. In particular, his work presents improved techniques for enhancing creativity for general students.

A supporter of the competency-based approach to enhancing creativity among students of a psychological profile should be considered. Grigor'evich Bermus (2018), whose works today are used as a methodological basis on the territory of higher educational institutions in Eastern Europe. At the same time, scientists such as Panok (2019) and Shevchenko (2019) work in the same field. In their works, the methodology for enhancing the creativity of psychology students was created, basing their principles and paradigms on the upcoming features of their profession, in particular in the field of psychological analysis and counselling. 
Such a specification brought their work to a new level because using their methods, students could train not only their creativity but also prepare themselves for future work.

To model the process of enhancing creativity, we have used the methodology of functional modelling. One of such modern methods of scientific knowledge is IDEF0 notation, which allows creating a functional model of the structure, functions, information flows and objects of the system under study. Initially, this model was used to a greater extent in the field of economics and modelling of basic business processes (Sylkin et al., 2019). Later, given the simplicity and visibility of the IDEF0 model, it has been used by various scientists for various purposes (Yanchuk \& Shulgan, 2019; Chernyaga \& Yanchuk, 2012; Wang et al., 2012; Po-Han et al., 2003; Yachmen, 2020).

But it is worth noting that the vast majority of authors whose work we investigated used this model at a basic level and only to simplify the processes that occur in their research system as much as possible. Yachmen (2020), who used IDEF0 modeling in the process of optimisation system of higher educational institutions, used it as a simple process structuring model, while our model is flexible since at each stage of its use it is possible to make adjustments using information about subprocesses, which affects the main stages of modelling.

Given all the previously presented work, today the issue of enhancing the creativity of psychology students is considered in many scientific circles. But despite such a numerous of scientific achievements, in each of them, in our opinion, there are still gaps in the field of specification and algorithmisation of a methodology for enhancing creativity among psychology students. Thus, it would be expedient to refine and make the algorithm of the methodology of increasing it.

\section{Methodology}

As noted by Weisberg (1988) the formation of professional creativity among future specialists is an extremely important component of the process of becoming a holistic personality, ready for professional creative activity. Creativity characterises the unity of perception, experiences, and actions that are accomplished in a new and original way, arise as an integral ability to find new connections and become aware of new relationships, a tendency to work and learn about innovations, brain activity, leads to new insights, to the transformation of experience into new organisations and the expression of an unprecedented constellation of meanings. Taking into account what has been said, the common denominator or determining principle of true professional skill of a specialist in the psychological profile is a full-fledged, creatively started, social thought activity that makes professional development in a differently and is based on the complementarity of the four components (Zhang \& Sternberg, 2009; Kerr \& Lloyd, 2008):

- fundamental knowledge of university graduates in the field of theoretical and applied sociology, general, social and age psychology, theory, methodology, and technologies of social work, the foundations of building a civil society and a democratic state;

- well-developed personality standards, formed skills of perfect professional activity, systematically characterise it as a competent specialist in a certain direction of social professionalism, which cannot to effectively solve everyday tasks of business everyday life but also to find optimal solutions to practical situations and personal problems; 
- gained values and psycho-spiritual forms or existential of human spiritualised life-realisation (holiness, freedom, faith, hope, love, creativity, responsibility, conscience, virtue, truthfulness, tolerance, empathy, etc.).

A prerequisite for the creation of psycho-didactic conditions for the development of professional creative abilities of future practical psychologists is the development of such a model that would reflect the system-forming set of causes and circumstances in creative knowledge and thus form the personality of a psychologist.

The leading psychological and pedagogical principles for the development and implementation of a personal-creative approach in teaching students is an orientation towards the conceptual model of personality; the relationship of psychodiagnostics and psychocorrection in the process of educational interaction; the system of creative development tools. Scientific and substantive development and implementation of the program for the development of the creative personality of the future psychologist and introducing of a personal and creative approach in the process of teaching students of psychological faculties based on of disclosing their creative potential will help to increase the productivity of training, form motivation for mastering professional skills.

This methodology can bring alternative ways of forming the process of developing the creative abilities of psychology students, serve as a platform for this process. We are not claiming that this methodology will have a direct impact on the development of creativity. Our attempts are focused on integrating this model into the process of developing creative abilities to facilitate and systematise the existing approaches and techniques for developing creativity in psychology students.

Moreover, modelling (in our case, the process of increasing creativity) is necessary in order to:

- understand how a specific object is built - what is its structure, basic properties, laws of development, and interaction with the environment;

- learn how to manage the development of materialised process and identify the best ways to manage it under given conditions (optimisation);

- predict the direct and indirect consequences of implementing of the given methods and forms of interaction on the object, process;

- make changes and track the results.

For the specification and algorithmisation of the methodology of increasing creativity among psychology students, we have chosen the methodology of functional modelling and a graphical description of processes (IDEF0) (Rikova, 2009).

Until recently, the IDEF0 model was used mainly in the formation of the structural organisation of business processes, as well as the construction of digital algorithms. Today, this model is actively used in the system of geodetic monitoring of technologically loaded territories by global positioning system observations (Chernyaga \& Yanchuk, 2012), in the processes of ordering land management objects (Yanchuk \& Shulgan, 2019), architectural design (Po-Han et al., 2003), construction project management (Chen et al., 2008), production processes (Davtyan \& Holod, 2019), enterprise labuor protection systems (Halil, 2016), military work simulation equipment (Wang et al., 2012). 
The functional model is a series of diagrams, namely context diagrams, decomposition diagrams, and other documents. Elements of the context diagram and decomposition diagrams are:

- function blocks;

- interface arcs.

The left side is the entrance. Input values correspond to the objects entering (entering) the block and turn into output values in it. The upper side corresponds to the control inputs. They, as a rule, should be specific control actions, documents, rules, standards, restrictions that determine the performance of functions by the unit. The right side is the output of the block. The initial values correspond to the results of the activity of the functional block, what the input quantities turn into. The lower side corresponds to the mechanisms. The mechanism provides the execution of functions, for example, equipment, specialists, as well as the necessary resources. This purpose of the sides of the blocks corresponds to system principles, namely: all actions are performed on some objects, are input.

The basic structure of the IDEF0 model is a set of source data, which consists of the following elements:

- the principal goal of modelling - to form a functional model IDEF0 for visual modelling and algorithmisation of the process of increasing the creativity of psychology students;

- the target audience of the model - psychology students, teachers and, staff of higher educational institutions that are involved in the educational process;

- context of the functional model - a list of functions and diagram objects of the functional model IDEF0;

- modelling technology - methodology of functional modelling IDEF0;

- technological support of simulation-program for the formation of the vector diagrams.

The process of implementing the methodology of enhancing the creativity of psychology students will consist of a certain set of stages. These steps will be further subdivided into subprocesses that will be guided by specific directives that are formed according to the stated purpose - to increase the creativity of psychology students.

The methodology we have developed is designed to help teachers organise and optimise the development process and show step-by-step the development of creativity in psychology students. Unfortunately, it is impossible to fully concretize the methods, technologies in each specific case that must be applied by teachers in order to develop creativity, because each person is individual. But this methodology will help form the primary backbone of the system for the development of creative abilities.

Taking this into account, the format of this article should be considered as ordinary research and testing the IDEF0 model to increase the creative abilities of psychology students.

To begin with, for the sake of initial detailing of this goal, we need to form a functional diagram of the highest level A- 0 , which will be primary in the process of building the functional model IDEF0. Thus, in the Figure 1, we have systematized the main and uppermost components of the system for increasing the creativity of psychology students. In the next, based on these stages, we will form the decomposition of the first and second levels. 
The scheme that we have developed makes it possible to see a list of main stages in increasing the creativity of psychology students. Such a simplified model, using IDEF0 functional mechanisms, will be further expanded and detailed to fully understand the whole algorithm of the process of increasing the creativity of psychology students.

It is worth noting that a feature of the structural blocks of the IDEF0 model is that each block implements the process of converting inputs to outputs using certain mechanisms and resources. Thus, having depicted the primary goal of our research in the form of A0 in Figure 1 , it would be advisable to depict the main initial elements that are necessary to achieve the goal (Figure 2).

Creating the conditions necessary to enhance creativity

A2

Activation of creative potential with the help of specially selected technologies of creative self-research and selfexpression.

A3

Analysis of the problems, limitations and locks that arise in the process of creativity, with their subsequent development.

A4

Consolidation of the skills acquired at the previous stages and the use of these skills in further professional activities.

Figure 1. The hierarchical structure of functional model IDEF0 of increasing the creativity of psychology students (source: created by authors)

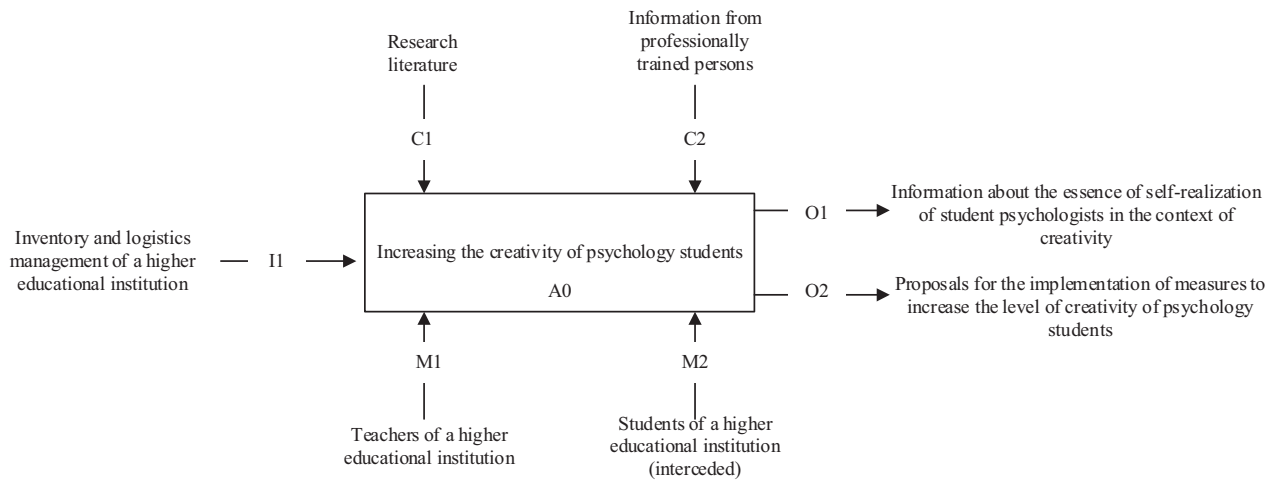

Figure 2. Functional structure of elements of model IDEF0 of increasing the creativity of psychology students (source: created by authors) 
For a better understanding of the model, it would be advisable to clarify in more detail all the above elements of the IDEF0 model we have built.

Input elements are marked with the symbol "I" and in our case are summarized as inventory and logistics management, which is used in the process's implementation of increasing the creativity of psychology students. This group includes both those resources that exist in a higher educational institution on a permanent basis, as well as the new inventory and logistics management that is necessary for the implementation of innovative activities.

Control objects were designated with the symbol "C":

$\mathrm{C} 1$ - research literature. This control element forms the totality of information that can be used in the process's implementationof increasing the creativity of psychology students;

$\mathrm{C} 2$ - information from professionally trained persons can include information that is provided from persons who have undergone certified training. The information submitted from them differs from the research literature because it is presented in the simplest and understandable form for recipients.

Mechanism objects were designated with the symbol " $M$ ":

M1 - teachers of a higher educational institution. These persons are one of the major participants in the educational process and it is on them that the role of both theoretical and personal development of students as assigned;

M2 - students of a higher educational institution. Since creativity reflects the comprehensive development of the individual, the ability to form the powerful and mutually beneficial interconnection between direct participants and colleagues is an important element. Given this, the indirect influence of students on their colleagues is a powerful mechanism for increasing creativity.

The last elements are the set of outputs that are achieved with the correct implementation of all the above elements of the functional model IDEF0. They were indicated by the symbol "O":

O1 - information about the essence of self-realisation of student psychologists in the context of creativity. This information is generated after all the proposed measures have been implemented and the opportunity is formed to evaluate the results;

$\mathrm{O} 2$ - proposals for the implementing of measures to increase the level of creativity of the psychology students. In the end, we get the most optimal solution according to the methodology of implementing the process of increasing the creativity of psychology students.

Having presented all the elements of the IDEF0 model we have constructed, it would be advisable to go over the specifications and details of the stages we have chosen. To do this, we built decompositions of the first level of the process of increasing the creativity of psychology students (Figure 3).

Considering the decomposition presented above, it would be advisable to explain in more detail the contents of each of the stages:

A1 - creating the conditions necessary to enhance creativity. The creation of these conditions implies the presence in the training group of an atmosphere of acceptance and trust. In the absence of such an atmosphere, it is necessary to create conditions conducive to its occurrence. At this stage, the use of technologies aimed at group interaction is recommended. With skillful application of these technologies, they can work out the basic defences related 


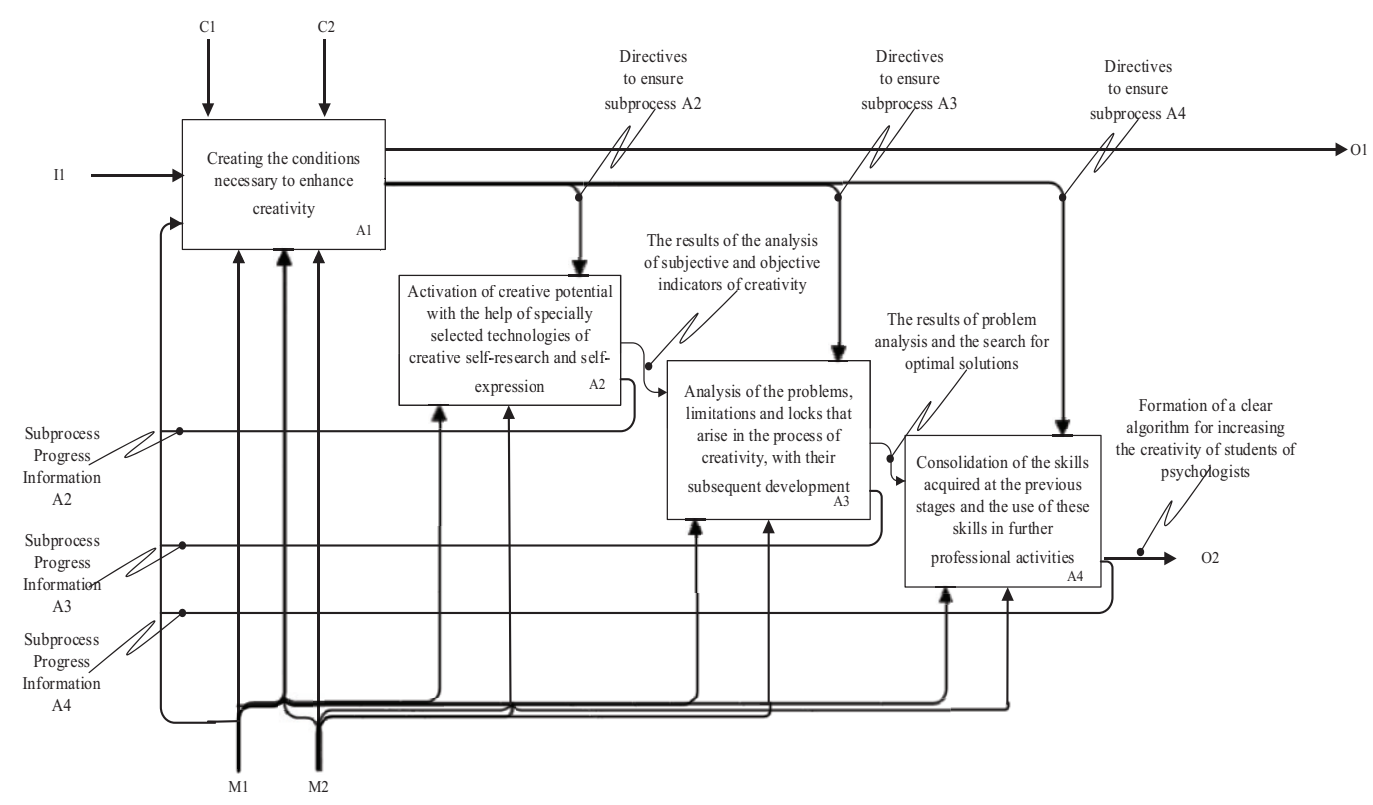

Figure 3. Decompositions of the first level of functional model IDEF0 of increasing the creativity of psychology students (source: created by authors)

to the fear of self-expression and self-presentation in a group in a fairly short time (Laycraft, 2012). It should be noted that it is not the eventual result or the product of creative expression that is of particular value, but the spectrum of emotions and discoveries that accompanied the creation of this product in the process of completing a task or exercise;

A2 - activation of creative potential with the help of specially selected technologies of creative self-research and self-expression. Work at this stage requires a certain level of basic trust of the group members to each other and the leader. If the previous stage of the work was successful, the level of trust is generated automatically. The component of creative expression in the learning process is associated with the uniqueness and originality of each student at any given time. Viewed in this aspect, the creative component becomes the development path without fear of making a mistake in any new action. The process of creativity also becomes the way of self-knowledge and expanding contact with others and with oneself, which results in an increase in the student's personality resource and a gradual expansion of the degree of freedom of application of practical skills acquired in the classroom (Hassan Hemdan \& Kazem, 2019);

A3 - analysis of the problems, limitations, and locks that arise in the process of creativity, with their subsequent development. This stage is carried out using technologies and techniques of role modelling. These technologies allow working with students in a softly and unobtrusively. Most of the locks are usually associated with topics that are relevant at a given time. In most cases, the occurrence of locks can be avoided in situations where the group has an atmosphere of reliability and security (Dickhut, 2003). It is worth noting the students that the content of the workshops is determined by the students themselves, and, therefore, depends on the completeness of the expression of their requests; 
A4 - consolidation of the skills acquired at the previous stages and the use of these skills in further professional activities. It is advisable to carry out this work using visualization and modelling techniques. These techniques allow designing the skills acquired in the learning process, with the aim of their fruitful use in the future. This stage forms an obvious idea for the teacher about the dynamics of increasing creativity in the group and gives the opportunity to make the necessary changes (Wells \& Dickens, 2020).

Separately, it is necessary to explain the intermediate inputs, outputs, control mechanisms, which are depicted in the form of arrows on the constructed functional model IDEF0. Intermediate inputs (control) and outputs comprise of the following elements:

- directives for process management A2, A3, A4 - these are the results of decision-making by the entities responsible for monitoring and control of this process;

- the output "Information on the progress of the process A2, A3, A4" - these are the information that the subjects responsible for monitoring and control receive from each sub-processes an increase in the creativity of psychology students. Based on this information, decisions are made on the completion of the sub-processes and the transition to the next.

It is worth noting that when studying the scientific literature that used the IDEF0 model, most scientists stopped at the first level of decomposition (Yachmen, 2020; Chernyaga \& Yanchuk, 2012; Po-Han et al., 2003). Given this, their model was presented as a basic algorithm that depicted the basic elements of the functioning of the system. In order to better detail the processes and structure of all mechanisms, we decided to form decompositions of the second level.

For the following specification and a more visual explanation of the process of increasing creativity among student psychologists, we have built the second-level decomposition of the functional model IDEF0 (Figure 4). This decomposition explains the process of implementing one stage of the general process of increasing the creativity of psychology students. For brevity, we described stage A2 (Activation of creative potential with the help of specially selected technologies of creative self-research and self-expression), but it is worth noting that this decomposition of the second level of the functional model IDEF0 can be applied to any of the stages. Moreover, the specificity of the functional model IDEF0 is that it always possible to form decompositions of the following levels, which will make it possible to explain in more detail the implementation of the process of increasing the creativity of psychology students.

In this case, the elements of the decomposition will be interpreted as follows:

A21 - determining the level of trust between teachers and psychology students. Trust is an important and determining element in the formation of a favourable learning environment among psychology students. Only if there is a certain level of trust between the student and the teacher, it becomes possible to increase the creativity of student psychologists;

A22 - analysis of the level of creative implementation of psychology students. The analysis of the initial and intermediate level of creativity is carried out using specific techniques of communication, modelling and other technologies. This will allow correctly and plan the following strategy and tactics;

A23 - the selection of appropriate technology to enhance the creativity of psychology students. Taking into account the stages, and having passed the appropriate directives for 


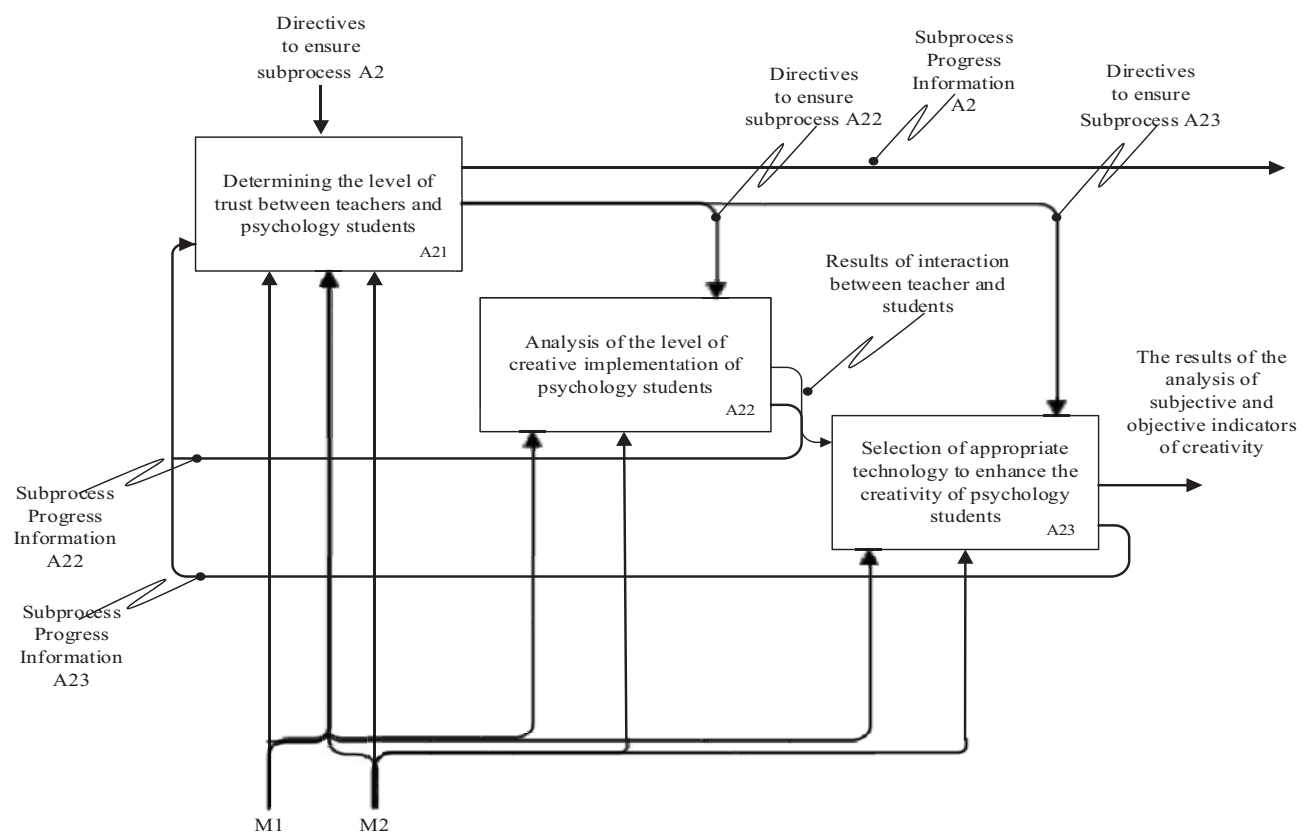

Figure 4. Decompositions of the second level of functional model IDEF0 of increasing the creativity of psychology students (source: created by authors)

control and monitoring, teachers have the opportunity to choose the most optimal methodology for increasing the creativity of psychology students.

Thus, using the IDEF0 functional model, we have revealed all the functional levels and structural elements of the process of enhancing the creativity of psychology students.

\section{Practical verification of the existing model}

In practice, a real higher educational institution Ukrainian Academy of Printing was taken, which is located in Eastern Europe and has a special faculty for training psychology students, to test the model we have formed for increasing the creativity of psychology students. To carry out this experiment, 10 teachers were selected, who chose 2 groups of students for implementing of our model, each of which comprised 10 students. All students studied at the undergraduate degree. The model was tested for one semester.

The application and verification of this model took place in several stages. At the first stage, the modelling technology was presented. In the second stage, the very process of its development was described, and also a local goal was formed, which was a set for this model by this particular educational institution. In the third stage, the key sub-processes were identified that are needed to achieve the goal. In the fourth and final stage, teachers and students had to follow the stages presented in a two-level decomposition.

The teachers were asked to use the model we presented in terms of student study groups, and in the next to test the convenience of this model and the success of the development 
of creative abilities in the studied student groups, in comparison with those that were subjected to standard teaching methods. In order to briefly describe all the stages of the application of this model, we have formed Table 1 . The criteria for the selection of teachers for this educational institution was the presence of experience in teaching, a high level of competence, and previous participation of these teachers in research work.

At the end of the study, the teachers using the method of remote interviews, taking into account the difficult epidemic situation in the world and the country, assessed the implemented model in the process of developing the creative abilities of psychology students. The interview was conducted in the form of a questionnaire which included basic questions about the success of the implementation of this model at each stage, and individual questions about possible adjustments to this model. Evaluation of the success of the goal of this model is to increase the creative abilities of students who came out of the subjective assessment of competent persons - teachers who compared the level of creativity of students in the control and experimental groups. As a result of the questionnaire survey, all teachers taking part in the experiment confirmed that this model greatly facilitated the process of increasing students' creativity in the formation's context of a clear algorithm for this process.

In their opinion, this methodology greatly facilitated the process of developing the creative abilities of psychology students, given that most of the standard methods do not have a clear systematization and algorithmisation.

The model that we have developed in the future may become a kind of informational basis, which should contribute to creative development, and the data that the performers will receive after passing through each of these stages must undergo a clear and comprehensive analysis. Given the analysis, the performers will be able to understand how effectively the individual stages of decomposition are implemented, which in turn will testify to the effectiveness of the process of increasing creativity in psychology students.

Table 1. The main steps of the practical implementation of the IDEF0 model in the process of developing the creative abilities of psychology students (source: created by authors)

\begin{tabular}{|l|l|}
\hline \multicolumn{1}{|c|}{ Practical stages } & \multicolumn{1}{|c|}{ What was done } \\
\hline $\begin{array}{l}\text { Acquaintance with students, } \\
\text { educational conversations }\end{array}$ & $\begin{array}{l}\text { Communication in a group and individually with each } \\
\text { student, definition, and classification of the group and } \\
\text { individual characteristics of students in development's } \\
\text { contextof creativity. }\end{array}$ \\
\hline $\begin{array}{l}\text { Construction of the IDEF0 model } \\
\text { taking into account the individual } \\
\text { and group characteristics of students }\end{array}$ & $\begin{array}{l}\text { Development of decomposition of the first, second, and, if } \\
\text { necessary, the next levels of the model IDEF0. }\end{array}$ \\
\hline Executing each step of the model & $\begin{array}{l}\text { Getting information about the progress of each process } \\
\text { and sub-process of the model IDEF0. If necessary, the } \\
\text { implementation of the adjustment of activities. }\end{array}$ \\
\hline $\begin{array}{l}\text { Evaluation of the success of applying } \\
\text { the model }\end{array}$ & $\begin{array}{l}\text { Evaluation of the success of the implementation and } \\
\text { development of creative abilities among students of the } \\
\text { study group. In the presence of a minimum successful result } \\
\text { or its absence, the formation of extra levels, decomposition, } \\
\text { and further individualization of the model. }\end{array}$ \\
\hline
\end{tabular}




\section{Study limits}

In the context of this research, we took a separate specialty for testing, but our model can be used in other specialties with of gradual adaptation of the crucial stages, taking into account the specifics of the specialty and the subjects of their use. Our work was a test of an already existing IDEF0 methodology for developing the creative abilities of psychology students.

\section{Conclusions}

Creativity as a value-personal category is the essential reserve of self-actualization of the personality and today, to a large extent, it acts as a kind of mechanism for adapting the student's personality to social changes. In order to internally correspond to modern reality, psychologists must not only adapt to a new situation but also be able to change it and develop at the same time.

The creativity of psychology students is a mandatory characteristic of a holistic personality, because of the appropriate psychological conditions and the high level of formation of his professional and personal qualities. We have determined that today there are a numerous of scientific works relates to both the process of increasing creativity in general students and only among psychology students. But despite the great scientific achievements, today there is no clear methodology for introducing measures to increase creativity among psychology students. Given this, we proposed to use the functional model as a permanent methodology, revealing all the elements of this process, the interaction between them, and the most optimal way to achieve the eventual result. The advantages of this model are the fact that at the planning stage, the executive structure can clearly form and evaluate the resources and mechanisms necessary to fulfil the goal. In our case, it will be defined as measures to increase the creativity of psychology students.

For better detailing and visualization of the process of increasing the creativity of psychology students, we used the IDEF0 functional model, with which it became possible to depict all the structural and functional elements of this process.

In the study presented by us, simulations using IDEF0 are displayed to increase creativity in psychology students a key feature and scientific novelty is the fact that we have taken an already existing mathematically proven and practically effective method for modelling the main stages of a process which was first taken to model such a specific process as increasing students' creativity. Evaluation of creativity is subjective in itself and is difficult to assess, investigate based on evidence or objective assessment. Considering all this, we realized that it would interest and relevant for the scientific and pedagogical community to reflect the stepby-step process of increasing such a phenomenon as the creativity of psychology students, taking into account all possible actions that can be at each stage. To do this, each crucial stage has its own sub-stages, that is, the decomposition of the first level can be detailed by the decomposition of the second, third levels, and so on. In addition, thanks to the IDEF0 model, it is possible to reflect the basic information and results about the progress of a stage, and to establish and describe the key directives to be followed. 


\section{References}

Baumeister, R. F., Schmeichel, B. J., \& DeWall, C. N. (2014). Creativity and consciousness: evidence from psychology experiments. In E. S. Paul \& S. B. Kaufman (Eds.), The Philosophy of Creativity: New Essays (pp. 185-198). Oxford University Press. https://doi.org/10.1093/acprof:oso/9780199836963.003.0010

Bruno, A., \& Dell'Aversana, G. (2017). Reflective practice for psychology students: the use of reflective journal feedback in higher education. Psychology Learning and Teaching, 16(2), 248-260. https://doi.org/10.1177/1475725716686288

Burkšaitienè, N. (2018). How can university learning environment contribute to students' creativity? Lithuanian students' perspective. Creativity Studies, 11(1), 162-171. https://doi.org/10.3846/cs.2018.271

Chen, Y., Jia Hu, J., \& Mo, P. (2008, 12-14 October). The development of the lifecycle function model by IDEF0 for construction projects. In Proceedings of 2008 4th International Conference on Wireless Communications, Networking and Mobile Computing. Dalian, China. https://ieeexplore.ieee.org/ stamp/stamp.jsp?arnumber $=4679950 \&$ casa_token $=511$ C5QhZbiMAAAAA:RZRlarfkK0vhcSPPHk 1QtT06CmD05zcOsvqFW4TpxK37uKq6FwIqa4vpfLT4GChH76iW7DMQ_VAX\&tag=1

Chernyaga, P., \& Yanchuk, O. (2012). The order of value access point for GPS: be careful in the minds of obscured appearances. New Access to Geodesic Science and Technology, 23, 53-56.

Cheung, Ch.-K., Rudowicz, E., Yue, X., \& Kwan, A. S. F. (2003). Creativity of university students: what is the impact of field and year of study? Journal of Creative Behavior, 37(1), 42-63. https://doi.org/10.1002/j.2162-6057.2003.tb00825.x

Davtyan, L. L., \& Holod, A. S. (2019). IDEF0-Model for rationalization management industrial pharmacy. Pharmaceutical Magazine, 6, 18-25.

Dickhut, J. E. (2003). A brief review of creativity. http://www.personalityresearch.org/papers/dickhut.html

Entrialgo, M., \& Iglesias, V. (2020). Entrepreneurial intentions among university students: the moderating role of creativity. European Management Review, 17(2), 529-542. https://doi.org/10.1111/emre.12386

Feist, G. J. (2010). The function of personality in creativity: the nature and nurture of the creative personality. In J. C. Kaufman \& R. J. Sternberg (Eds.), The Cambridge handbook of creativity (pp. 113-130). Cambridge University Press. https://doi.org/10.1017/CBO9780511763205.009

Fekula, M. J. (2011). Managerial creativity, critical thinking, and emotional intelligence: convergence in course design. Business Education Innovation Journal, 30(2), 92-102.

Goodman, S. (2015). Fuel creativity in the classroom with divergent thinking. George Lucas Educational Foundation "Edutopia". https://www.edutopia.org/blog/fueling-creativity-through-divergentthinking-classroom-stacey-goodman

Grigor'evich Bermus, A. (2018). Problemy i perspektivy realizatsii kompetentnostnogo podkhoda v obrazovanii. Eidos. https://studfile.net/preview/6268118/

Halil, V. V. (2016). Security management of the Republic of Belarus on methodologies of IDEF0. Information Processing Systems, 9, 203-207.

Hassan Hemdan, A., \& Kazem, A. M. (2019). Creativity development of high-achieving students. Creativity Research Journal, 31(3), 296-308. https://doi.org/10.1080/10400419.2019.1641684

Kerr, Ch., \& Lloyd, C. (2008). Pedagogical learnings for management education: developing creativity and innovation. Journal of Management and Organization, 14(5), 486-503. https://doi.org/10.5172/jmo.837.14.5.486

Kondakov, I. (2020). Metodologicheskiye osnovy zarubezhnykh teoriy professional'nogo razvitiya. Psihologicheskie problemy, 25(2), 158-164.

Langebæk, R., Tanggaard, L., Toft, N., \& Berendt, M. (2020). Using creativity as an educational tool in 
veterinary surgery: students' perceptions and surgical performance. Journal of Veterinary Medical Education, 47(1), 91-99. https://doi.org/10.3138/jvme.1117-175r1

Laycraft, K. Cz. (2012). The development of creativity: a study of creative adolescents and young adults [PhD/Doctoral Thesis, University of Calgary]. Canada. https://prism.ucalgary.ca/bitstream/handle/11023/166/ucalgary_2012_laycraft_krystyna.pdf?sequence $=2$

Ling, M. K. D., \& Loh, S. Ch. (2020). Relationship of creativity and critical thinking to pattern recognition among Singapore private school students. The Journal of Educational Research, 113(1), 59-76. https://doi.org/10.1080/00220671.2020.1716203

Lopukhova, O. G. (2014). Dynamics of psychology students' "Image of a Psychologist" conception during education. Procedia - Social and Behavioral Sciences, 159, 120-124.

https://doi.org/10.1016/j.sbspro.2014.12.341

Navickienè, V., Sederevičiūtè-Pačiauskienè, Ž., Valantinaitè, I., \& Žilinskaitè-Vytienè, V. (2019). The relationship between communication and education through the creative personality of the teacher. Creativity Studies, 12(1), 49-60. https://doi.org/10.3846/cs.2019.6472

Panok, V. (2019). Kontseptual'no pidkhodyty do formal'nosti praktykuyuchoho psykholoha. Praktychna psykholohiya ta sotsial'na robota, 4, 75-97.

Po-Han, Ch., Tiong, L. K., \& Laiyun, W. (2003). Information sharing and exchange in the architectural design and structural design phase. Civil Engineering Research, 6, 28-30.

Proctor, R. W., \& Capaldi, E. J. (2001). Improving the science education of psychology students: better teaching of methodology. Teaching of Psychology, 28(3), 173-181. https://doi.org/10.1207/S15328023TOP2803_02

Renzulli, J. S. (1992). A general theory for the development of creative productivity through the pursuit of ideal acts of learning. Gifted Child Quarterly, 36(4), 170-182. https://doi.org/10.1177/001698629203600402

Rikova, L. L. (2009). Strukturnyye i funktsional'nyye modeli, kotoryye meneye rasprostraneny v yestestvennykh i matematicheskikh naukakh. Pedagogicheskaya nauka: istoriya, teoriya, praktika, tendentsii razvitiya, 3. http://www.intellect-invest.org.ua/pedagog_editions_e-magazine_pedagogical_science_arhiv_pn_n3_2009_st_8/

Runco, M. A., \& Acar, S. (2012). Divergent thinking as an indicator of creative potential. Creativity Research Journal, 24(1), 66-75. https://doi.org/10.1080/10400419.2012.652929

Sanz de Acedo Baquedano, M. T., \& Sanz de Acedo Lizarraga, M. L. (2012). A correlational and predictive study of creativity and personality of college students. The Spanish Journal of Psychology, 15(3), 1081-1088. https://doi.org/10.5209/rev_SJOP.2012.v15.n3.39398

Shandruk, S. (2020). Spetsifika podgotovki prakticheskikh psikhologov $k$ professional'noy deyatel'nosti: problemy podgotovki i povysheniya kvalifikatsii prakticheskikh psikhologov v vysshikh uchebnykh zavedeniyakh (pp. 32-36). Kyiv.

Shevchenko, N. (2019). Funktsionuvannya profesiynoyi svidomosti psykholoha v protsesi psykholohichnoho konsul'tuvannya. Problemy suchasnoyi psykholohiyi, 3(1), 95-101.

Smith, J. K., \& Smith, L. F. (2010). Educational creativity. In J. C. Kaufman \& R. J. Sternberg (Eds.), The Cambridge handbook of creativity (pp. 250-264). Cambridge University Press. https://doi.org/10.1017/CBO9780511763205.016

Sylkin, O., Kryshtanovych, M., Zachepa, A., Bilous, S., \& Krasko, A. (2019). Modeling the process of applying anti-crisis management in the system of ensuring financial security of the enterprise. Business: Theory and Practice, 20, 446-455. https://doi.org/10.3846/btp.2019.41

Wang, H., Gong, G., Xie, J., Cai, Sh., \& Zheng, Y. (2012, 27-30 October). Research on IDEFo and UML combination based modeling of equipment support. In T. Xiao, L. Zhang, \& M. Fei (Eds.), 
AsiaSim2012: Asia Simulation Conference 2012: Shanghai, China, October 2012. Proceedings, Part I. Series: Communications in Computer and Information Science. Vol. 323 (pp. 46-54). Shanghai, China. Springer.

Weisberg, R. W. (1988). Problem solving and creativity. In R. J. Sternberg (Ed.), The Nature of Creativity: Contemporary Psychological Perspectives (pp. 148-176). Cambridge University Press.

Welch, R., Alfrey, L., \& Harris, A. (2020). Creativity in Australian health and physical education curriculum and pedagogy. Sport, Education and Society. https://www.tandfonline.com/doi/pdf/10.1080 /13573322.2020.1763943?casa_token=AO8o0_we2zYAAAAA:AeNfQ5_NdhbLXLHRQaqRCw395PSZcyj2hakSGC_FCnDwDehMw9VyeVeCiA1XmVm61x65ZweVwB-

Wells, P. C., \& Dickens, K. N. (2020). Creativity in counselor education classroom: more than case studies. International Journal for the Advancement of Counselling, 42, 191-199. https://doi.org/10.1007/s10447-019-09393-7

Yachmen, F. (2020). Functional model initial mortgage in IDEF0. Business Information, 4, 91-98.

Yanchuk, O., \& Shulgan, R. B. (2019). Resheniye zadach zemleustroystva i kadastra s ispol'zovaniyem matematicheskoy modeli dlya soznaniy nevazhnykh. Zhurnal Natsional'nogo universiteta vodnoy gosudarstvennosti i kritiki prirody: tekhnologii, 3, 293-300.

Zhang, L.-F., \& Sternberg, R. J. (2009). Intellectual styles and creativity. In T. Rickards, M. A. Runco, \& S. Moger (Eds.), The Routledge companion to creativity (pp. 256-266). Series: Routledge Companions. Routledge. https://doi.org/10.4324/9780203888841.ch21 